\title{
Migration and Global Justice
}

Migration is without a doubt one of the most significant phenomena of contemporary world politics. Moreover, its political and social importance is destined to increase. Today, more -and more diverse- people are moving internationally to an ever more varied set of destinations, making migration a phenomenon of increasing magnitude and complexity. This increasing complexity calls for a deeper and more nuanced empirical understanding of migration in all its forms, it challenges longstanding normative and legislative frameworks, and raises new and difficult questions for political and legal theorists as well as policy makers. This at a time when a system of migration governance is emerging at the bilateral, regional and even global level, moving away from traditional understandings of migration regulation and management as a strictly state concern.

As a contribution to this growing field, this collection addresses the relationship between migration and global justice in general, and migration and development in particular. It brings together theoretical and empirical analysis in an interdisciplinary framework that tackles different aspects of the relationship.

Alex Sager's contribution tackles the question of the relationship between migration and distributive justice by addressing the implications of empirical theories of migration for normative accounts of migration and distributive justice. Through a critical appraisal of sociological and economic theories of migration, Sager provides us with an account of how national and global economic, political, and social institutions determine migration flows. Thus, we gain new insights on the moral questions that a normative theory of migration needs to address, but that have so far been neglected.

One of the first, perhaps obvious, ways in which migration can be discussed within a global justice framework is to consider the question of what mobility rights we believe individuals should have under conditions of justice at the global level, or in general, which principles must shape a just migration policy, either for single states or for regional and even global institutions. Three contributions in this collection consider the principles that should regulate migration in what, they argue, are sub-optimal conditions. Aveek Bhattacharya considers the arguments in favour of a migration lottery - where all those who desire to migrate are entered into a lottery, and the winners are given the opportunity to migrate - in a world where substantively free migration is impossible given individual lack of resources. Thus, all those who desire to migrate have an equal opportunity to do so, since they all are equally likely to be lottery winners. He concludes against it, 
however, arguing that a commitment to freedom in general does not recommend that we adopt a lottery system for determining who can and cannot cross borders.

In a research note, Theresa Scavenius considers the feasibility of otherwise defensible transnational rights, such as freedom of movement, within the political context of the European Union today. She spells out an under-explored questions of how freedom of movement within the European Union affects the 'packages' of socioeconomic and political rights that member states sustain, and whether the justifications for freedom of movement subsequently change.

Finally, Jaakko Kuosmanen's contribution tackles an interesting and often neglected issue in the study of forced migration, namely, the question of justice between states in carrying out duties to refugees. Specifically, the author examines states' obligations towards asylum seekers in circumstances of partial compliance. He concludes that complying states which have the capacity to assist asylum seekers can have an obligation of justice to assist them beyond their allocated "share" when other states unjustly default on their responsibilities.

The rights of migrants are not the only important consideration in debates about global justice and migration. Migration, and particularly temporary migration, is often treated as an efficient mechanism of wealth re-distribution and an effective tool of development aid. However, concern has been expressed both about the effectiveness of migration as a distributive justice and development tool and about the degree of protection afforded to individual migrants' rights in the context of policies that may be otherwise justified on the basis of redistributive justice and development goals. Four of the contributors to this issue tackle these questions.

Katharina Eisele, in her contribution, addresses directly the issue of migrants' rights within migration and development policies by discussing the EU's policy on this topic under the Global Approach to Migration and Mobility. She notes how the human rights of migrants were only very recently explicitly acknowledged across the Global Approach to Migration and Mobility. The author highlights the dangers of disregarding the protection of migrants' rights, and questions the appropriateness of placing the 'development burden' on immigrants without the guarantee of secure legal status in the host countries.

Francis Cheneval and Johan Rochel concentrate on one of the central, and most contested, questions in the debate on migration and development: remittances. In particular, the contribution argues that remittances should be taken into account when defining an ethical framework on migration. The authors emphasize two normative grounds for the positive consideration of remittances, first, remittances increase individual migrants' autonomy by allowing them to take control of their lives and lift themselves out of poverty, second, if appropriate labour legislation 
to facilitate the process is set up, it would allow receiving countries to fulfil their duty of assistance to poor sending countries. Both grounds, the authors argue, speak in favour of a liberalization of migration policy.

The next two contributions address a second issue of fundamental and growing importance in discussions of migration as a tool of global justice: temporary labour migration. Christine Straehle analyses the case of Live-In-Caregivers in Canada, as an example of the programs that have been defended on the basis of wealth redistribution. She challenges this defence by underlining a morally problematic aspect of the program: their resulting in the vulnerability of individual migrant workers. In this situation, important conditions of the migrants' individual autonomy are compromised. She argues that these problems outweigh any potential redistributive effect such migration programs may have. Giselle Valarezo's and Christine Hughes' contribution concentrates on Canadian temporary migrant programs as well, in particular on Guatemalans who migrate to Canada to work in agriculture on a seasonal basis. The authors detail the migrants' efforts at political organization, via the creation of a political advocacy group - Asociación de Guatemaltecos Unidos por Nuestros Derechos.

This special issue, we believe, constitutes an important contribution to the debate on global justice and migration by fostering an interdisciplinary dialogue that brings together different perspectives, both empirical and theoretical, on important questions in this growing field. 